\title{
Role of early experience in ant enslavement: a comparative analysis of a host and a non-host species Rumsaïs Blatrix* and Claire Sermage
}

Address: Laboratoire d'Ethologie Expérimentale et Comparée CNRS UMR 7153, Université Paris 13, 99 av. JB Clément 93430 Villetaneuse, France

Email: Rumsaïs Blatrix* - blatrix@leec.univ-paris13.fr; Claire Sermage - c_sermage@hotmail.com

* Corresponding author

Published: 02 August 2005

Frontiers in Zoology 2005, 2:13 doi:10.1 186/1742-9994-2-13
Received: 15 June 2005

Accepted: 02 August 2005

This article is available from: http://www.frontiersinzoology.com/content/2/1/13

(C) 2005 Blatrix and Sermage; licensee BioMed Central Ltd.

This is an Open Access article distributed under the terms of the Creative Commons Attribution License (http://creativecommons.org/licenses/by/2.0), which permits unrestricted use, distribution, and reproduction in any medium, provided the original work is properly cited.

\begin{abstract}
Background: Ants use the odour of the colony to discriminate nestmates. In some species, this odour is learned during the first days following emergence, and thus early experience has a strong influence on nestmate discrimination. Slave-making ants are social parasites that capture brood of other ant species to increase the worker force of their colony. After emerging in the slave-maker nest, slave workers work as if they were in their own colony. We tested the hypothesis that early experience allows the deception of commonly enslaved species, while non-host species use a different mechanism, which does not involve learning.
\end{abstract}

Results: Pupae of a host species, Temnothorax unifasciatus, and a non-host species, T. parvulus, were allowed to emerge in the presence of workers of one of two slave-maker species, Chalepoxenus muellerianus or Myrmoxenus ravouxi. When T. unifasciatus was exposed to slave-makers for 10 days following emergence, they were more aggressive towards their own sisters and groomed the slavemaker more. $T$. parvulus gave a less clear result: while workers behaved more aggressively towards their sisters when exposed early to $C$. muellerianus workers, this was not the case when exposed early to $M$. ravouxi workers. Moreover, $T$. parvulus workers allogroomed conspecific nestmates less than $T$. unifasciatus. Allogrooming activity might be very important for the slave-makers because they are tended by their slaves.

Conclusion: Our findings show that early experience influences nestmate discrimination in the ant $T$. unifasciatus and can account for the successful enslavement of this species. However, the nonhost species $T$. parvulus is less influenced by the early environment. This might help to explain why this species is never used by social parasites.

\section{Background}

The early stages of an animal's life constitute a critical period during which the environment can have dramatic and sometimes irreversible effects on adult behaviour. The best example is imprinting, a process by which the individual develops an irreversible reference pattern from a stimulus present during a short period of time during its development. Lorenz [1] was the first to conceptualize the imprinting process and gave one of the most striking examples: during the few minutes after hatching, young birds developed an attachment to their parents if present, or a parental surrogate, such as Lorenz himself. Imprinting is only a special case of the processes by which early experience affects subsequent adult behaviour. For instance, in monkeys and humans, Harlow \& Harlow [2] and Bowlby [3] noted the importance of attachment 
during the early phase after birth for the development of adult behaviour.

Despite a much simpler brain structure, insects display similarly pronounced plastic responses to the early environment. Influences of the preimaginal environment on adult behaviour have been demonstrated as early as the late 1930's in Drosophila [4], and were later documented and shown to be involved in various contexts in many other species (see review in [5]). These contexts can have a social dimension in social insects. Some ants, for example, learn the colony odour during the early phase of imaginal life and later use this template for recognizing brood [6-11] and discriminating among adults [12-15]. This critical period determines who benefits from altruistic behaviours shown by worker ants, which rarely reproduce directly but rely on indirect fitness benefits via reproduction of related individuals [16].

Slave-making ants are social parasites that exploit the labour force of other ant species. Slave-maker workers are specialized for conducting raids, wherein they seize brood from nearby host ant colonies and bring them back to their own nest [17]. When they emerge, the slave ants behave as if they were in their own colony. Among other routine ant tasks, they rear the slave-maker brood, defend the nest, and sometimes feed and groom the slave-maker workers. Altruistic acts of slaves are thus directed toward unrelated individuals. One hypothesis suggests that slave deception is possible because slaves are captured as pupae and learn the slave-maker colony odour after emergence [18-20].

Myrmoxenus ravouxi and Chalepoxenus muellerianus are among the most common slave-makers in Western Europe. They use several related species as slaves but show a preference for Temnothorax unifasciatus [21]. In the Mediterranean area, M. ravouxi, C. muellerianus and T. unifasciatus can be found in sympatry with $T$. parvulus, though $T$. unifasciatus seems to prefer more arid environments. $T$. parvulus has never been found as a slave, but the reason for this is unknown. We postulated that slavery would be prevented if nestmate discrimination in T. parvulus was not achieved through early learning of colony odour, because slave workers emerging in the slave-maker colony would recognize the slave-maker brood and workers as aliens.

Our study had two aims. First, we tested the hypothesis that deception of the host $T$. unifasciatus ensues from early learning of colony odour as a mechanism for nestmate discrimination. Second, we tested the hypothesis that early experience (within the first 10 days following emergence) affects the discrimination capabilities of $T$. parvulus workers less than those of T. unifasciatus. After manipulat- ing the early experience of $T$. unifasciatus and $T$. parvulus, we tested and compared their discrimination capabilities.

\section{Results}

T. unifasciatus workers reared with M. ravouxi (batch A) or C. muellerianus (batch B) were significantly more aggressive towards their unfamiliar sisters than towards the familiar M. ravouxi or C. muellerianus workers (Table 1). Moreover they spent significantly more time allogrooming the familiar M. ravouxi or C. muellerianus workers than their unfamiliar sisters. Similarly, T. unifasciatus workers reared with conspecifics (batch $\mathrm{C}$ ) were less aggressive towards their familiar sisters than towards the unfamiliar $M$. ravouxi and C. muellerianus workers. They also spent significantly less time allogrooming the unfamiliar $M$. ravouxi or $C$. muellerianus workers than the familiar sisters (Table 1).

T. parvulus workers reared with M. ravouxi (batch A) did not show a significant difference in aggressive behaviour or in the time spent allogrooming between their unfamiliar sisters and the familiar M. ravouxi workers (Table 1 ). Conversely, $T$. parvulus workers reared with C. muellerianus (batch B) were significantly more aggressive towards their unfamiliar sisters than towards the familiar C. muellerianus workers, and they spent significantly more time allogrooming the familiar C. muellerianus workers than the unfamiliar sisters. T. parvulus workers reared with conspecifics (batch $\mathrm{C}$ ) were significantly less aggressive towards their familiar sisters than towards the unfamiliar $M$. ravouxi or $C$. muellerianus workers, but the time they spent allogrooming the unfamiliar $M$. ravouxi or C. muellerianus workers and their familiar sisters was much reduced and did not differ significantly (Table 1).

T. unifasciatus and T. parvulus workers reared with conspecifics (batch $\mathrm{C}$ ) did not show any significant difference in the number of aggressive acts towards $M$. ravouxi $(6.3 \pm$ 3.2 and $3.4 \pm 1.5$ respectively, $\mathrm{Z}=1.2, \mathrm{p}=0.22)$ or $C$. muellerianus $(3.2 \pm 1.4$ and $3.2 \pm 1.8$ respectively, $\mathrm{Z}=0, \mathrm{p}=$ $0.99)$. However, T. unifasciatus workers reared with conspecifics (batch C) spent significantly more time allogrooming familiar sisters than did $T$. parvulus $(19.3 \pm 13.4$ and $0.1 \pm 0.1$ respectively, $Z=2.6, p=0.01$ ).

\section{Discussion}

Our results suggest that the environment experienced by T. unifasciatus during the first 10 days after emergence influences nestmate discrimination, at least in our artificial laboratory conditions. Indeed, workers that were exposed early to M. ravouxi and C. muellerianus displayed a very aggressive behaviour towards their own sisters and spent much time grooming the slave-makers. This suggests that the influence of the early environment could potentially account for the fact that $T$. unifasciatus slaves 
Table I: Discrimination capabilities of two ant species after manipulation of their early experience. Number of agonistic acts and duration (in seconds) of allogrooming behaviours of $T$. unifasciatus and $T$. parvulus workers tested during 10 minutes towards a $M$. ravouxi, $C$. muellerianus or a homospecific worker. Test workers were reared for 10 days after emergence either in the presence of $M$. ravouxi (batch A), C. muellerianus (batch B) or nestmate workers (batch C).

\begin{tabular}{|c|c|c|c|c|c|c|c|c|}
\hline species tested & treatment $(\mathrm{N}, \mathrm{C})^{*}$ & species presented & aggression (mean $\pm \mathrm{SE}$ ) & Z & $P$ & grooming (mean \pm SE) & Z & $P$ \\
\hline \multirow[t]{8}{*}{ T. unifasciatus } & batch $\mathrm{A}(22,10)$ & M. ravouxi & $0.3 \pm 0.2$ & \multirow{2}{*}{3.2} & \multirow{2}{*}{$<0.002$} & $16.5 \pm 5.9$ & \multirow{2}{*}{3.2} & \multirow{2}{*}{$<0.002$} \\
\hline & & T. unifasciatus & $14.3 \pm 6.4$ & & & $0.4 \pm 0.4$ & & \\
\hline & batch B $(22,10)$ & C. muellerianus & $0.8 \pm 0.5$ & \multirow{2}{*}{3.5} & \multirow{2}{*}{$<0.001$} & $30.8 \pm 9.5$ & \multirow{2}{*}{3.4} & \multirow{2}{*}{$<0.001$} \\
\hline & & T. unifasciatus & $14 \pm 4$ & & & $0.03 \pm 0.03$ & & \\
\hline & batch $C(22,10)$ & M. ravouxi & $6.3 \pm 3.2$ & \multirow{3}{*}{2.3} & \multirow{3}{*}{0.02} & $0.9 \pm 0.9$ & \multirow{3}{*}{2.4} & \multirow{2}{*}{0.019} \\
\hline & & & & & & & & \\
\hline & & T. unifasciatus & $0.5 \pm 0.3$ & & & $19.3 \pm 13.4$ & & \\
\hline & & C. muellerianus & $3.2 \pm 1.4$ & 2 & 0.047 & $2.5 \pm 2.3$ & 2.1 & 0.033 \\
\hline \multirow[t]{9}{*}{ T. parvulus } & batch A $(22,5)$ & M. ravouxi & $2.8 \pm 1.6$ & \multirow{2}{*}{0.4} & \multirow{2}{*}{0.69} & $2.7 \pm 1.9$ & \multirow{2}{*}{1.6} & \multirow{2}{*}{0.11} \\
\hline & & T. parvulus & $2 \pm 0.8$ & & & $0 \pm 0$ & & \\
\hline & batch B $(23,8)$ & C. muellerianus & $1.9 \pm 0.7$ & \multirow{2}{*}{2.3} & \multirow{2}{*}{0.02} & $4.9 \pm 3.6$ & \multirow{2}{*}{2.4} & \multirow{2}{*}{0.018} \\
\hline & & T. parvulus & $4.6 \pm 1.4$ & & & $0 \pm 0$ & & \\
\hline & batch C $(22,8)$ & M. ravouxi & $3.4 \pm 1.5$ & \multirow{3}{*}{2} & \multirow{3}{*}{0.049} & $3.5 \pm 2.4$ & \multirow{3}{*}{0.7} & \multirow{3}{*}{0.47} \\
\hline & & & & & & & & \\
\hline & & T. parvulus & $0.2 \pm 0.1$ & & & $0.1 \pm 0.1$ & & \\
\hline & & & & \multirow[t]{2}{*}{2.5} & \multirow[t]{2}{*}{0.013} & & \multirow[t]{2}{*}{1.3} & \multirow[t]{2}{*}{0.50} \\
\hline & & C. muellerianus & $3.2 \pm 1.8$ & & & $0 \pm 0$ & & \\
\hline
\end{tabular}

\footnotetext{
$* \mathrm{~N}$ : number of ants tested; C: number of colonies the test ants originated from.
}

care for and defend the slave-makers. However, as host workers never emerge only with slave-makers present the mechanisms allowing enslavement could be different in nature. The same result was obtained for T. parvulus workers that were exposed to C. muellerianus. However, when exposed to $M$. ravouxi, they were not more aggressive toward their sisters than toward the slave-maker. These results partly confirm our hypothesis that the effect of early experience on the discrimination capabilities is reduced in $T$. parvulus when compared with $T$. unifasciatus workers.

The use of tethered, but live ants to record the reaction of test workers could have influenced their behaviour through the performance of antennation, biting, stridulation, etc., and the emission of pheromones. Indeed, several species of social parasites are known to use repellent, appeasement, and/or propaganda substances to usurp host nests [22]. The occurrence of such substances in our focal slave-maker species is likely and could have reduced aggressiveness of test workers. Moreover, several pupae of the test species were allowed to emerge in the glass tubes containing slave-makers. The early experience of test workers could then have been influenced by the other emerging test workers. Another potential source of bias in our results is the unequal representation of collected populations of Temnothorax in the experimental groups. The observed differences between our T. parvulus and T. unifasciatus might be due to differences between populations rather than species, if early experience had a smaller influence on nestmate discrimination in the Italian population. However, this possibility seems unlikely because species differences for fundamental mechanisms (such as the determinant of nestmate discrimination) are expected to be unaffected by population differences. The observed differences between the two species cannot be due to a mere difference in aggressiveness, because their levels of aggression towards slave-makers in the control experi- 
ment were not significantly different. However the difference between their levels of allogrooming was highly significant. A low basic level of allogrooming activity for T. parvulus workers was probably responsible for the fact that they did not groom their sisters more than the slavemakers in the control experiment. This makes it difficult to test the influence of early experience on allogrooming behaviour of $T$. parvulus.

Few other studies have demonstrated that early experience with slave-maker workers or brood elicits slave-maker care in the host species [23-25]. These studies dealt with species in the subfamily Formicinae; specifically, the slavemaker Formica sanguinea and its hosts F. fusca and F. cunicularia. Slave-making ants are known from only two subfamilies: the Formicinae and the Myrmicinae [26]. In the only study considering Myrmicinae, Alloway and Hare [27] showed that early learning was not necessary to explain the acceptance of the brood of the slave-maker Protomognathus americanus by enslaved T. longispinosus workers. Indeed, slave-maker larvae were preferentially accepted even when $T$. longispinosus workers were exposed early to conspecific larvae. Our results confirm that early experience can be important for successful ant enslavement in other myrmicine systems. Together, these studies across subfamilies seem to confirm the hypothesis that early behavioural plasticity of certain ant species has permitted or at least facilitated the evolution of slave-making habits [28], and show that other mechanisms are possible [27] but seem less common. This suggests that early behavioural plasticity could be a general prerequisite for the evolution of slave-making in ants [20]. The fact that early experience is important for the integration of the young slaves into the slave-maker colony might explain why $M$. ravouxi and C. muellerianus do not capture adult hosts during raids $[29,30]$. In fact, out of 10 genera displaying interspecific slavery, only one is known to result in the mixing of adult slaves into the slave-maker colony [26]: raids of the slave-making Strongylognathus commonly end in the fusion with the Tetramorium host nest [31]. However, the fusion occurs after a prolonged fight that often results in casualties on both sides. It is noteworthy that intraspecific colony fusion has been reported in the genus Tetramorium as a result of territorial competition [26].

For some slave-making species, host colony take-over by slave-maker queens requires acceptance by adult host workers that have had no previous exposure to slave-makers. The founding queen of many slave-making species has to enter a host nest, be accepted by the host workers, then kill and replace the resident queen [19]. Once the slave-making queen manages to kill the resident queen, the workers care for the new queen and rear her brood. The acceptance of the new queen does not require previ- ous exposure to slave-makers because specialised behavioural and chemical strategies are involved [22]. For example, in the genus Polyergus, the young slave-maker queen does not bear any odour, and thus prevents the host workers from detecting her. The slave-maker queen then acquires the cuticular hydrocarbons of the host queen by physical contact and the host workers accept her as though she were there natal queen $[32,33]$. The founding queen of $M$. ravouxi enters the Temnothorax host nest, reaches the queen, and slowly throttles her to death [34]. The chemical mechanism responsible for the acceptation of the $M$. ravouxi queen by the host workers remains to be elucidated.

Queens of other slave-making species including C. muellerianus, Harpagoxenus and Protomognathus evict all adult ants from the host nest and keep only the host brood. They thus rely completely on the manipulation of early experience even during colony foundation. The life history of slave-making ants suggests that the use of adult slaves without previous exposure to the slave-maker is costly or involves a highly specialised strategy. Manipulation of early experience by the slave-maker appears as the most parsimonious strategy, which reinforces the suggestion that it facilitated the evolution of slavery.

Early behavioural plasticity is a widespread mechanism in animals and is involved in a number of host-parasite systems. However, in most cases, this mechanism is used by the parasite to find its host. The European cuckoo is known to rely on habitat, probably in addition to other cues, which is learned when reared by the host [35], but it does not seem to imprint directly on the host [36]. In parasitoid wasps, preimaginal imprinting is involved in host selection [5]. In slave-making ants, imprinting was also shown to influence host selection during raids and colony foundation $[37,38]$.

A striking result of this study was that manipulating the early experience of $T$. parvulus had different consequences depending on the slave-maker species to which it was exposed; nestmate discrimination seemed to be influenced by C. muellerianus, but not by M. ravouxi. If T. parvulus was insensitive to experience at emergence due to a strict genetic system of odour discrimination or an earlier sensitive period, we would expect the same outcome for both slave-maker species. A possible explanation is that there is a limited set of odours that $T$. parvulus can learn and/or perceive at emergence. $M$. ravouxi and C. muellerianus likely have different chemical profiles and T. parvulus might be chemically more similar to C. muellerianus than to $M$. ravouxi. Thus, the latter could be out of the range of potentially learned patterns. As we show in our experiments, phylogenetically closely related ant species can display various sensitivities to the early environment. Thus, 
perhaps the mechanisms of nestmate discrimination differ as well.

Nestmate discrimination has been shown to be less influenced by social environment at emergence in the ant genus Camponotus than in the genus Formica [7]. It is therefore interesting that no species of Camponotus is parasitized by slave-makers, while many Formica species are hosts to slave-makers. Similarly, our results on T. parvulus, the non-slave species, suggest that plasticity at emergence is not the only determinant of nestmate discrimination. A first alternative possibility is that nestmate discrimination is determined during an earlier sensitive period. Indeed, studies in Camponotus floridanus and Cataglyphis cursor demonstrated the importance of larval stages for nestmate discrimination [39,40]. As most slave-makers capture pupae preferentially, a nestmate discrimination mechanism based on larval experience might prevent these species from being enslaved. A second possibility is that nestmate discrimination in T. parvulus has a genetic component or is based on self-referent phenotype matching. $T$. nylanderi, a species very closely related to $T$. parvulus, has nestmate discrimination cues based on colony environment, and especially nest site material [41]. Even if $T$. parvulus can be expected to rely in part on a similar mechanism in the field, it could not have influenced our results because colonies were reared in identical artificial nests. Whatever the determinant of nestmate discrimination in this species, it can be an obstacle to slavery because at least some elements of the template involved in discrimination are established before the slaves are captured. Moreover, T. parvulus workers do not groom their nestmates often, which could be problematic for the slavemakers because they are tended by the slaves. These characteristics might partly explain why $T$. parvulus has never been found as slave. However, other factors could explain why $M$. ravouxi and C. muellerianus does not enslave $T$. parvulus. Social parasites in the tribe Formicoxenini are phylogenetically closely-related to their hosts [42]. It might be impossible for the social parasites to exploit more distant species as hosts because they would not share the same ecological and microhabitat requirements, or the same communication system. Slave-maker species could also be under selection to match the colony odour of the host species. Coevolution occurs between slavemaking ants and their hosts $[43,44]$ and it has been shown that in slave-maker colonies both species have similar cuticular hydrocarbon profiles $[45,46]$. It might therefore be easier for the host species to learn the more similar profile of the parasite, than for the non-host species.

\section{Conclusion}

Early experience can have important consequences on the behaviour of adult ant workers and consequently on their inclusive fitness. Manipulation of early experience in an experimental (this study) or natural (social parasitism) context influences nestmate discrimination. However, we showed that the effect varies across species: it was more pronounced in the host than in the non-host species. Social parasitism is not evenly distributed in ants: most of the 200 known species occur in only two subfamilies (the Formicinae and the Myrmicinae), and in these subfamilies it is concentrated in a few genera [47]. The reasons for this distribution are still unknown and elucidating the fine scale mechanisms involved in nestmate discrimination across taxa might help to explain the evolution of slavery in ants.

\section{Methods}

Colonies of the two slave-maker species and of both host species were collected in northern Italy (Lago di Garda) and southern France (Vaison-la-Romaine and Grasse, we found no slave-makers near Grasse) in the spring and summer 2003. Because of a sampling bias, significantly more T. unifasciatus originated from southern France and more $T$. parvulus from northern Italy (Chi-square $=13, \mathrm{p}=$ 0.022 ). Nests were housed in plastic boxes containing a thick layer of plaster. The print of a microscope slide covered by a glass plate provided a nest site [48]. Colonies were fed twice a week with frozen fruit flies and a mixture of honey and apple. Rearing conditions were as follows: day/night: $14 \mathrm{~h}-24^{\circ} \mathrm{C} / 10 \mathrm{~h}-17^{\circ} \mathrm{C}$. Genus names comply with Bolton's new classification of Formicidae [49]. The experiments were performed in August and September 2003.

Pupae of T. unifasciatus and T. parvulus that were close to emergence were removed from their colonies (unparasitized) and isolated in glass tubes with either $M$. ravouxi (experimental batch A), C. muellerianus (experimental batch B) or homo-colonial (control batch C) workers. Each glass tube contained one to three pupae (from the same colony) and two to six adult workers. The small numbers of slave-maker workers available precluded larger worker/pupae ratios, but at least two adult workers were used for each pupa. Slave-maker workers of $M$. ravouxi and C. muellerianus were obtained from 20 and 27 colonies respectively. Pupae close to emergence were recognizable by pigmentation, and emergence took place within two days of uniting pupae with their respective conditioning workers. Amputation of the distal segments of one leg of adult Temnothorax workers from batch $\mathrm{C}$ allowed us to distinguish them unambiguously from the newly emerged test workers. Slave-makers from batches A and $\mathrm{B}$ were not subjected to this amputation. Workers were tested $10 \pm 0.3$ (mean $\pm \mathrm{SE}$ ) days after emergence.

Each test worker was introduced into a circular arena of $1.5 \mathrm{~cm}^{2}$ where another worker was tethered by a nylon thread tied between the head and alitrunk. We were only 
interested in the behaviour of the test worker, thus we tethered the other worker to reduce the probability of interaction. Tethered workers could, however, still emit pheromones and engage in various other behaviours such as antennation, biting, stridulation etc. Tests started at least five minutes after tethering in order to let the tethered worker acclimate, but we cannot totally exclude the influence of pheromones on the behaviour of test workers. Duration of allogrooming and number of agonistic acts (mandibles opening, biting, stinging attempts) towards the tethered worker were recorded over $10 \mathrm{~min}$ utes (from the first encounter). Each test worker from batches A and B was tested successively against a slavemaker worker (M. ravouxi or C. muellerianus respectively) from its glass tube (hetero-colonial and familiar) and a worker from its colony of origin (homo-colonial and unfamiliar). Test order was controlled. Duration of allogrooming and number of agonistic acts were compared between the two tests using the Wilcoxon test for paired samples. Each test worker from batch $\mathrm{C}$ was tested successively against a worker from its glass tube (homo-colonial and familiar), a M. ravouxi worker, and a C. muellerianus worker (hetero-colonial, unfamiliar). All combinations of test order were equally represented. The test involving the homo-colonial and familiar worker was compared to each of the two tests involving a slave-maker worker using the Wilcoxon test for paired samples. Moreover, the number of agonistic acts towards the slave-makers was compared between T. unifasciatus and T. parvulus with a Mann-Whitney test for independent samples in order to test for a difference in levels of aggression between the two species. Differences in duration of allogrooming between the two species were similarly tested by comparing the performances of test workers from batch $\mathrm{C}$ in tests involving a homo-colonial and familiar worker. Tests were computed with Statistica 6.

\section{Authors' contributions}

$\mathrm{RB}$ conceived the study, carried out part of the experiments and data analysis, and drafted the manuscript. CS participated in the design of the study, carried out part of the experiments and data analysis. Both authors read and approved the final manuscript.

\section{Acknowledgements}

We thank Paul Devienne and Rémi Dillys for help with ant collecting, Stéphane Chameron for discussions and Jeremy Bono for correcting the English text. Andreas Schulz helped with species identification.

\section{References}

I. Lorenz K: The companion in the bird's world. Auk 1937, 54:245-273.

2. Harlow HF, Harlow MK: Learning to love. Am Sci 1966, 54:244-272.

3. Bowlby JA: Critical phases in the development of social responses in man and other animals. New Biology 1953, 1 4:25-37.
4. Thorpe WH: Further studies on preimaginal conditioning in insects. Proc R Soc Lond B 1939, 127:424-433.

5. Caubet $Y$, Jaisson $P$, Lenoir A: Preimaginal induction of adult behaviour in insects. $Q$ J Exp Psychol $B$ 1992, 44: 165- 178.

6. Jaisson $P$ : Note préliminaire sur l'ontogenèse du comportement de soin au couvain chez la jeune fourmi rousse (Formica polyctena Forst): Rôle d'un mécanisme probable d'imprégnation. C R Acad Sci, D, Sci Nat 1972, 275:272 I-2723.

7. Carlin NF, Halpern R, Hölldobler B, Schwartz P: Early learning and the recognition of conspecific cocoons by carpenter ants (Camponotus spp.). Ethology 1987, 75:306-316.

8. Hare JF, Alloway TM: Early learning and brood discrimination in leptothoracine ants (Hymenoptera: Formicidae). Anim Behav 1987, 35:1720-1724.

9. Le Moli F, Passetti M: Olfactory learning phenomena and cocoon nursing behaviour in the ant Formica rufa L. Boll Zool 1978, 45:389-397.

10. Le Moli F, Mori A: Early learning and cocoon nursing behaviour in the red wood ant Formica lugubris Zett. (Hymenoptera: Formicidae). Boll Zool 1982, 49:93-97.

II. Fénéron R, Jaisson P: Ontogeny of nestmate brood recognition in a primitive ant, Ectatomma tuberculatum Olivier (Ponerinae). Anim Behav 1995, 50:9-14.

12. Morel L: Relation entre comportement agressif et privation sociale précoce chez les jeunes immatures de la fourmi Camponotus vagus Scop. (Hymenoptera: Formicidae). $C R$ Acad Sci, D, Sci Nat 1983, 296:449-452.

13. Errard C: Role of early experience in mixed-colony odor recognition in the ants Manica rubida and Formica selysi. Ethology 1986, 72:243-249.

14. Carlin NF, Hölldobler B: The kin recognition system of carpenter ants (Camponotus spp.). I. Hierarchical cues in small colonies. Behav Ecol Sociobiol 1986, 19:123-134.

15. Alloway TM, Ryckman D: Learned social attachment to queens in Leptothorax ambiguus Emery ant workers. Behaviour 1991, I 1 8:235-243.

16. Hamilton WD: Altruism and related phenomena, mainly in social insects. Ann Rev Ecol Syst 1972, 3:193-232.

17. Buschinger A: Evolution of social parasitism in ants. Trends Ecol Evol 1986, I:I55-160.

18. Jaisson P: Kinship and fellowship in ants and social wasps. In Kin recognition Edited by: Hepper PG. Cambridge, Cambridge University Press; 1991:60-93.

19. D'Ettorre $P$, Heinze J: Sociobiology of slave-making ants. Acta Ethol 200I, 3:67-82.

20. Le Moli F: On the origin of slaves in dulotic ant societies. Boll Zool 1980, 47:207-212.

21. Buschinger A: Socially parasitic formicoxenine ants from Western Europe - a review (Hymenoptera, Formicidae). In Proceedings of the International Colloquia on Social Insects Volume 3-4. Edited by: Kipyatkov VE. St. Petersburg, Russian Language Section of the IUSSI, Socium; 1997:I-9.

22. Lenoir A, D'Ettorre P, Errard C, Hefetz A: Chemical ecology and social parasitism in ants. Ann Rev Entomol 200I, 46:573-599.

23. Le Moli $F$, Mori $A$ : Why a slave ant species accepts and cares for cocoons of its slave-maker. Insectes Soc 1987, 34:|36-I4I.

24. Le Moli $F$, Mori $A$ : The influence of the early experience of worker ants on enslavement. Anim Behav 1985, 33:1384-1387.

25. Jaisson $\mathrm{P}$ : L'impregnation dans l'ontogenèse des comportements de soins aux cocons chez la jeune fourmi rousse (Formica polyctena Forst.). Behaviour 1975, 52:1-37.

26. Hölldobler B, Wilson EO: The ants. Cambridge, Belknap Press; 1990:732.

27. Alloway TM, Hare JF: Experience-independent attraction to slave-maker ant larvae in host-species ant workers (Leptothorax longispinosus; Hymenoptera: Formicidae). Behaviour 1989, 11 0:93-105.

28. Jaisson P: L'imprégnation dans l'ontogenèse du comportement de soins aux cocons chez les formicines. In Proceedings of the 7th International Congress of the IUSSI London, United Kingdom, ; 1973:176-181.

29. Buschinger A, Ehrhardt W, Winter U: The organization of slave raids in dulotic ants - a comparative study (Hymenoptera; Formicidae). Z Tierpsychol 1980, 53:245-264. 
30. Schumann RD: Raiding behavior of the dulotic ant Chalepoxenus muellerianus (Finzi) in the field (Hymenoptera: Formicidae, Myrmicinae). Insectes Soc 1992, 39:325-333.

31. Sanetra M, Güsten R: The socially parasitic ant genus Strongylognathus Mayr in North Africa (Insecta: Hymenoptera: Formicidae). Zootaxa 200I, 20:I-20.

32. D'Ettorre $P$, Errard $C$ : Chemical disguise during colony founding in the dulotic ant Polyergus rufescens Latr. (Hymenoptera, Formicidae). Insect Soc Life 1998, 2:7I-77.

33. Johnson CA, Vander Meer RK, Lavine B: Changes in the cuticular hydrocarbon profile of the slave-maker ant queen, Polyergus breviceps Emery, after killing a Formica host queen (Hymenoptera: Formicidae). J Chem Ecol 200I, 27:1787-I804.

34. Buschinger A: Evolution, speciation, and inbreeding in the parasitic ant genus Epimyrma (Hymenoptera, Formicidae). J Evol Biol 1989, 2:265-283.

35. Teuschl Y, Taborsky B, Taborsky M: How do cuckoos find their hosts? The role of habitat imprinting. Anim Behav 1998, 56:1425-1433

36. Brooke ML, Davies NB: A failure to demonstrate host imprinting in the cuckoo (Cuculus canorus) and alternative hypotheses for the maintenance of egg mimicry. Ethology 199|, 89:154-166.

37. Schumann RD, Buschinger A: Imprinting effects on host-selection behaviour of colony-founding Chalepoxenus muellerianus (Finzi) females (Hymenoptera, Formicidae). Ethology 1994, 97:33-46.

38. Schumann RD, Buschinger A: Imprinting effects on host-selection behavior of slave-raiding Chalepoxenus muellerianus (Finzi) workers (Hymenoptera: Formicidae). Ethology 1995, 99:243-25I.

39. Isingrini M, Lenoir A, Jaisson P: Preimaginal learning as a basis of colony-brood recognition in the ant Cataglyphis cursor. Proc Natl Acad Sci USA 1985, 82:8545-8547.

40. Carlin NF, Schwartz PH: Pre-imaginal experience and nestmate brood recognition in the carpenter ant, Camponotus floridanus. Anim Behav 1989, 38:89-95.

4I. Heinze J, Foitzik S, Hippert A, Hölldobler B: Apparent dear-enemy phenomenon and environment-based recognition cues in the ant Leptothorax nylanderi. Ethology 1996, 102:510-522.

42. Baur A, Sanetra M, Chalwatzis N, Buschinger A, Zimmermann FK Sequence comparisons of the internal transcribed spacer region of ribosomal genes support close relationships between parasitic ants and their respective host species (Hymenoptera: Formicidae). Insectes Soc 1996, 43:53-67.

43. Foitzik S, DeHeer CJ, Hunjan DN, Herbers JM: Coevolution in host-parasite systems: behavioural strategies of slave-making ants and their hosts. Proc $R$ Soc Lond B 200I, 268: I I39-I I 46.

44. Hare JF, Alloway TM: Prudent Protomognathus and despotic Leptothorax duloticus: differential costs of ant slavery. Proc Natl Acad Sci USA 200I, 98: I2093-12096.

45. Kaib M, Heinze J, Ortius D: Cuticular hydrocarbons profiles in the slave-making ant Harpogoxenus sublaevis and its hosts. Naturwissenschaften 1993, 80:281-285.

46. Brandt M, Heinze J, Schmitt T, Foitzik S: A chemical level in the coevolutionary arms race between an ant social parasite and its hosts. J Evol Biol 2005, 18:576-586.

47. Wilson EO: The insect societies. Cambridge, Harvard University Press; | $97 \mid: 548$.

48. Blatrix R, Herbers JM: Intracolonial conflict in the slave-making ant Protomognathus americanus: dominance hierarchies and individual reproductive success. Insectes Soc 2004, 5I:131-138.

49. Bolton B: Synopsis and classification of Formicidae. Mem Amer Entomol Inst 2003, 7 I:I-370.

\section{Publish with BioMed Central and every} scientist can read your work free of charge

"BioMed Central will be the most significant development for disseminating the results of biomedical research in our lifetime. "

Sir Paul Nurse, Cancer Research UK

Your research papers will be:

- available free of charge to the entire biomedical community

- peer reviewed and published immediately upon acceptance

- cited in PubMed and archived on PubMed Central

- yours - you keep the copyright
Biomedcentral 